\title{
OF ENGINEERED TOMATOES
}

SANTA CRUZ, Calif.--No more cardboard tomatoes. Consumers may be able to buy tomatoes from their grocer that are as good as what they could grow in their back yards: plump, juicy, red, and tasty. But these aren't Big Boys. They're probably Flavr Savrs or some other genetically manipulated variety of Lycopersicon esculentum. And now that the U.S. Food and Drug Administration (Bethesda, MD) has declared that foods developed through biotechnology are not dangerous and, with rare exceptions, can be regulated just like ordipect such tomatoes on their grocer's shelves sometime next year.

U.S. consumers already put away about 18 pounds of tomatoes per person per year, or about $\$ 3$ billion worth. Still, consumers are far from satisfied with the quality: of 31 common grocery items included in a U.S. Department of Agriculture (USDA, Washington, DC) consumer-satisfaction survey, tomatoes ranked dead last.

Why haven't commercial growers been nary foods, consumers may actually exable to address this problem? Because

twice as long as conventional breeds. The Flavr Savr tomato is engineered by antisense RNA technology to suppress the production of a softening enzyme, polygalacturonase (PG), which attacks pectin in the cell walls of ripening fruit. All other aspects of the ripening process-including flavor development and a change in color-continue unabated. Calgene scientists isolated a complementary DNA clone of the tomato PG gene and inserted it in to select commercial varieties in the antisense orientation. Plants expressing the antisense construct exhibit significant decreases in PG activity-up to 99 percent. And experimental results indicate that the trait is stably inherited.

Other efforts to affect ripening in tomatoes center on manipulating the biochemical pathway for ethylene biosynthesis. Ethylene is synthesized from methionine via S-adenosylmethionine (SAM) and 1-aminocyclopropane-1-carboxylic acid (ACC), catalyzed by ACC synthase. It is possible to interfere with this pathway by preventing the formation of ACC-either by blocking the

\section{Companies are engineering tomatoes to improve flavor.}

of the constraints involved in handling perishable produce. Growers have to pick their tomatoes green and hard. To ripen these tomatoes, suppliers gas them with ethylene, mimicking and triggering the fruit's built-in ripening mechanism. And what about taste? Well, growers don't count flavor as one of the more important characteristics of a commercial tomato. Flavor, in fact, is an illdefined quality, resulting from the complex interaction of possibly hundreds of different biochemical compounds. Commercial growers believe that by the time a tomato is mature, it has received from the plant all the vitamins, sugars, and other nutrients it will ever get. It will ripen the same off the vine as on it.

\section{Calgene}

But researchers don't agree. At Calgene (Davis, CA), for instance, the premise is that vine-ripened fruit tastes better. To this end, Calgene has genetically engineered a tomato, called Flavr Savr, that can be left to ripen on the vine and still be firm enough to ship. "Once they're in the supermarket, they will soften normally," says Calgene's director of tomato research, William Hiatt. In fact, Flavr Savr stays fresh for two weeks after vine-ripe harvesting, nearly activity of ACC synthase per se or by catalyzing the cleavage of ACC by ACC deaminase (ACCD) -or by degrading SAM via SAM hydrolase.

Pioneering work on ACC synthase was performed by plant molecular biologist Athanasios Theologis and coworkers at the Plant Gene Expression Center (Albany, CA), which is operated by USDA's Agricultural Research Service and the University of California. The researchers antisensed gene expression of ACC synthase to block ethylene production in transgenic tomatoes. Three of 34 transgenic plants showed a marked inhibition of ethylene production and a delay in the onset of fruit ripening. In fact, the antisense fruits never did ripen naturally-they had no aroma and didn't turn red or soft. But when scientists added exogenous ethylene to reverse the inhibition, the fruits were "indistinguishable from naturally ripened fruits with respect to texture, color, aroma, and compressibility," says Theologis. He adds that the tomatoes stayed on the vine longer-up to five months in the greenhouse-without deteriorating, so they had more time to take up "sugars and acids important to flavor." USDA has licensed its ACC synthase technology to Calgene,
Monsanto (St. Louis, MO), and DNA Plant Technology (DNAP, Cinnaminson, NJ).

\section{Agritope}

Meanwhile, researchers at Agritope (Beaverton, OR) have chosen to interfere with ethylene biosynthesis by focusing on SAM hydrolase expression. Their first experiments, in tobacco, used bacteriophage-T3-encoded SAM hydrolase to generate transgenic plants with a reduced capacity to synthesize ethylene. Richard Bestwick, James Stamp, and coworkers then switched to tomatoes. With the goal of obtaining stagespecific and tissue-specific SAM hydrolase gene expression, the scientists employed tomato's E8 promoter. The native E8 gene is only expressed in ripening fruit beginning at the mature green stage. It worked: SAM hydrolase expression was indeed restricted to ripening fruit. Researcher Stamp explains that Agritope is now examining the genetic construct's effect on post-harvest ripening. The goal, he says, is to slow down fruit ripening or even stop it at a certain stage until the fruit is ready for shipping.

\section{DNAP}

Approaching the ethylene pathway from a slightly different angle is DNAP, which has developed a technology it terms transwitch. In transwitch technology, the gene of interest is duplicated; inserting an exact copy of the gene back into the plant "inhibits the translation of RNA into protein, but how that happens is not completely well characterized," says a DNAP spokesman.

Meanwhile, amidst the flurry of genetic manipulations, DNAP researchers have long been developing an improved tomato using somaclonal variation, a method based on culturing plant somatic cells to generate single gene mutations, chromosomal variants, and changes in multi-gene traits. The company is currently field testing a somaclonal tomato that, it says, can be harvested just as the first shades of pink start to appear. Ripening proceeds after harvest without ethylene. DNAP plans to test market the tomato in 1993.

Which of these strategies is likely to be most effective at producing a marketable tomato that's just as wonderful as one hot off the backyard vine? Agritope's Stamp feels that none of the technologies for controlling ethylene production has really been proven yet. He adds that it may well be a combination of approaches that will finally produce the ideal product. -Jennifer Van Brunt 